\title{
Lessons from the Recent Recession: The Faster They Grow, the Harder They Fall
}

Fernando M. Martin, Senior Economist

$\mathrm{U}$ S. gross domestic product (GDP) contracted significantly and persistently during the recent financial crisis and recession. Lessons can be learned from comparing the U.S. experience with that of other industrialized countries.

The chart shows real GDP per capita from 1991:Q1 to 2012:Q4 for the United States, Canada, the United Kingdom, France, and Germany expressed as percentage deviations from the U.S. average for 1991. That is, the starting point for each country is its GDP per capita relative to that for the United States stated in purchasing power parity (PPP) terms. ${ }^{1}$

Prior to the most recent recession (2007:Q4-2009:Q2), U.S. real GDP per capita grew an average of 2.1 percent per year. It then contracted by 6 percent in less than two years and, after the recession ended, resumed growth but at a slower pace of 1.3 percent per year. As of 2012:Q4, U.S. GDP per capita remains about 15 percent below its pre-crisis trend.

Canada experienced similar changes. In 1991, its real GDP per capita was about 15 percent lower than that in the United States. It then grew an average of 2.2 percent per year before falling by 5 percent during the recession. Post-recession growth resumed at a more modest 1.6 percent per year and by 2012:Q4 remained about 14 percent below its pre-crisis trend.

In 1991, U.K. real GDP per capita was 30 percent less than that in the United States and catching up in the pre-crisis period, growing 2.9 percent per year. The effects of the crisis, however, were more severe and persistent in the United Kingdom than in the United States and Canada. U.K. GDP per capita dropped by 7.3 percent in less than two years and then vir- tually stopped growing after that. By 2012:Q4, it was about 22 percent below its pre-crisis trend.

Before the crisis, French real GDP per capita grew at a slower pace than that in the United States, Canada, and the United Kingdom, at around 1.6 percent per year. Its drop during the recession was proportionately similar to that in Canada, but its post-crisis growth most resembles the U.K. experience. By 2012:Q4, French GDP per capita was roughly at the same level as two years earlier and about 12 percent below its pre-crisis trend.

From 1991 to 2007, German real GDP per capita grew 1.3 percent per year, a significantly slower pace than that in the United States. The drop in German output during the crisis was concurrent with that in the United States and of

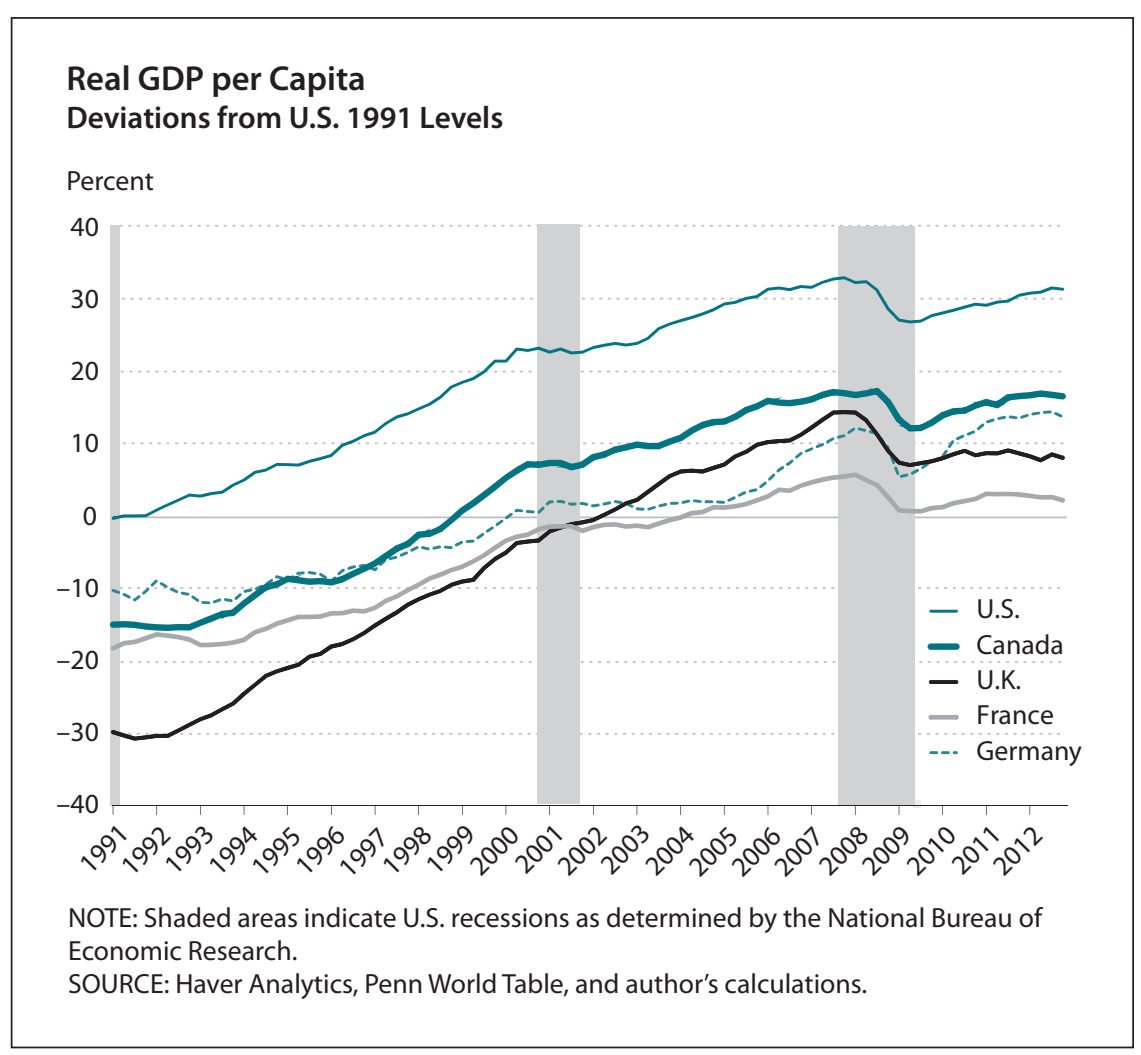




\section{The experience of several industrialized countries suggests a strong negative correlation between growth rates and the severity of the recent crisis. Monetary policy does not appear to have been a main driver of the post-recession recovery.}

a similar proportion (5 percent). However, Germany's experience in the aftermath of the crisis was very different: It recovered relatively quickly, and its GDP per capita has been back on trend for more than two years. Although Germany weathered the financial crisis and recession much better than the United States, it has arguably managed this performance at a substantial cost. In 1991, PPP output per capita for Germany was 90 percent of that for the United States; in 2010 (the date of the most recent Penn World Table data), the figure dropped to 82 percent.
Two key lessons may be drawn from these varied experiences. First, based on the countries analyzed, there appears to be a strong negative correlation between growth rates and the severity of the recent crisis. This result appears to generalize to other industrialized countries as well. After adding Italy, Spain, and Japan to the analysis, the correlation between pre-crisis growth rates and the 2012 output gap was $-0.79 .^{2}$ Second, the experiences of the United Kingdom, France, and Germany suggest that monetary policy may not have been a main driver of the recovery. Both France and Germany belong to the euro zone and, as such, share a common monetary policy. However, as noted, output contracted persistently in France and only temporarily in Germany. On the other hand, although the United Kingdom has allowed its inflation rate to increase well above its target since mid-2009, it is nevertheless experiencing stalled growth similar to that of France.

\footnotetext{
Notes

${ }^{1}$ The initial position is calculated using "PPP converted GDP per capita" from the Penn World Table, version 7.1.

${ }^{2}$ Here, the output gap is defined as the difference between real GDP per capita and its 1991-2007 trend.
} 